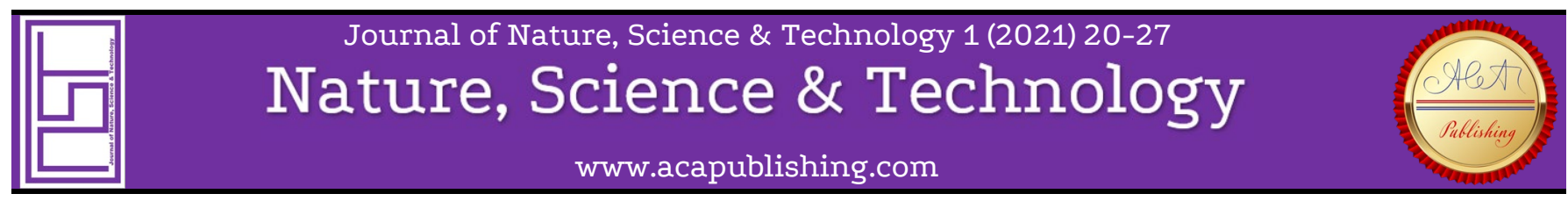

Review Article

\title{
Insulation Properties of Bricks with Waste Rubber and Plastic: A Review
}

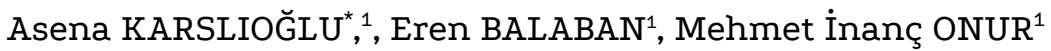 \\ ${ }^{1}$ Eskisehir Technical University, Faculty of Engineering, Civil Engineering Department, Eskisehir, Turkey
}

\section{Keywords}

Brick,

Waste,

Rubber,

Plastic,

Insulation.

\begin{abstract}
Traditional bricks are made of clay or cement. However, it has environmental deficiencies as causing high energy consumption and carbon dioxide emission. In addition, excessive and senseless use of non-renewable natural resources around the world causes social, economic and environmental damages. For these reasons, researchers have used several waste materials in brick production to contribute to sustainable development by optimizing environment-material-economy. In this study, the latest papers in the literature on the use of waste rubber (WR) and polyethylene terephthalate (PET) in brick production are presented. In particular, its thermal and sound insulation properties are examined. The literature review reveals the potential of the raw materials to be replaced by WR and PET when the manufactured bricks meet the standards.
\end{abstract}

\section{Introduction}

Brick is an ancient and essential earth material dating back to 8000 BC during the Egyptian, Mesopotamian and Roman times [1, 2]. Brick is the second most used construction material after concrete, is the most basic material used in the building of low-cost houses and multistorey apartments $[3,4]$. Traditional procedures of brick making are sequentially mixing soil-based materials, molding, drying, and then firing until a certain strength is achieved. However, the excessive use of soil materials has caused a large consumption of raw resources and high energy consumption in the production of terracotta bricks [5]. In addition, Ordinary Portland Cement is used to produce concrete bricks and is manufactured from cement and sand.

Waste materials which known as chemical, toxic or non-rotting, pose great threat to the environment. The amount of waste materials such as rubber (WR) and plastic (WP) is rapidly increasing. They can be classified as non-putrescible materials that polluter of environment.

The number of vehicles increasing day by day in the world directly affects the amount of waste production. While approximately 1.5 billion waste tires emerge each year, this number is predicted to reach 5 billion per year by 2030 [6]. It takes a long time for the tires to decompose in natural environment due to their weather resistance and non-biodegradation. Tire burning is the most common method of get rid of waste tires, because it is the easiest and cheapest way of annihilation of waste tires. Burning waste tire may cause fire hazards, produce harmful compounds which are threats health of living things. In addition, residual dust left after burning contaminates the soil. These outcomes cause a great environmental pollution.

A stack of WP from household items has become a major problem in the last two decades. Plastic pollution is a widespread and expanding problem. The global annual plastic production increased by $2.5 \%$ from 2018 to 2019, and 368 million tons were produced in 2019 [7]. Plastic waste stream includes high density polyethylene (HDPE), low density polyethylene (LDPE), Polyethylene terephthalate (PET), Polypropylene (PP) and Polystyrene (PS) wastes. Plastic wastes are not biodegradable and contain various toxic chemicals cause environmental pollution by polluting the soil, air and water. In addition, throwing and burning waste materials create a lot of pollution and smoke, posing an enormous danger for the environment and people in the long term [8].

Recycling techniques are constantly being improved through research and development activities in the industry. Many techniques have been proven effective in protecting nature. The recycling of materials such as WR and WP creates a model for better environmentally friendly annihilation of these materials. At the same time, waste processing and re-use becomes a serious economic problem. Therefore, it is very critical to attempt the utilization possibilities of these wastes. In addition, it is clear that WR and PET will remain a problematic issue in the future.

Waste management is a form of management that includes the reduction of waste, separation according to its properties and collection, recycling and disposal. The purpose of waste management is to recycle waste in order to achieve high rates of recycling and to prevent the consumption of raw materials. Figure 1 shows that the waste management scheme. 1,717,88 tons of waste was recycled in Turkey in 2019. Recycled wastes contain 177,611 tons of WR and 484 thousand tons of WP [9].

The utilization of WR and PET in the construction industry can contribute to both the prevention of environmental pollution and the design of economical buildings. Today, the desire to use cheaper, nature friendly and lightweight construction materials leads to the improvement of insulator materials such as mortar and brick by using WR and PET. In order to reduce environmental pollution, the amount of waste and the depletion of raw materials, therefor contributing to environmentally friendly approaches, many researches are trying to prove the usability of WR and PET in bricks.

This review paper submits the latest research updates on the usage of WR and WP to produce bricks. The insulation properties of bricks containing WR and PET are also emphasized. (t)

(A.Karslıoğlu Orcid: 0000-0001-5178-4069)
Received 02 Feb 2021 Revised 07 Feb 2021 Accepted 07 Feb 2021 Journal of Nature, Science \& Technology 1 (2021) 20-27
$2757-7783$ (c) 2019 ACA Publishing. All rights reserved. https://doi.org/10.36937/janset.2021.001.004 


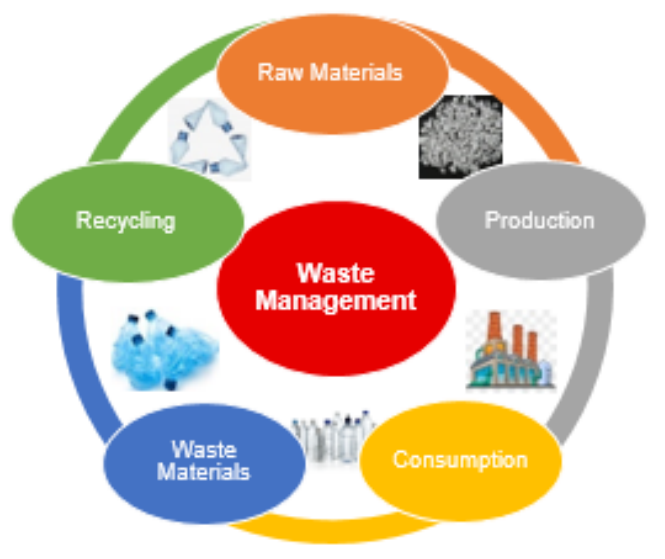

Figure 1. Waste management scheme

2. Review of researches on the incorporation of $W R$ and PET to produce brick

Material composition of bricks has been changed since the brick was first produced. Today, bricks are mostly made of burnt clay, sand and cement. Utilization of waste materials instead of these materials that make up the brick will help sustainable development. In this section, the mechanical and insulation properties of sustainable bricks using WR and PET are examined.

\subsection{The evaluation of WR in brick}

Crumb rubber (CR) obtained from the annihilation of waste tires causes environmental pollution worldwide due to major disadvantages such as their chemical composition [10]. For this reason, utilization of WR instead of sand in geopolymer interlocking bricks is an uncommon approach to solve this problem. Al-Fakih et al (2020) [11] examined CR which the fine sand was replaced $10-50 \%$ by volume used in geopolymer interlocking bricks. Also, 10-70\% fly ash (FA) as a replacement for cement by volume was used. According to ASTM C90 [12], the load-bearing wall unit must have a minimum compressive strength of $13.7 \mathrm{MPa}$. In order to obtain a compressive strength of $15 \mathrm{MPa}$, the amount of CR should be $10 \%$ and FA should be $56 \%$. As seen in Figure 2, result of the research was found that a rubberized interlocking brick (RIB) gave results acceptable results according to the standards.

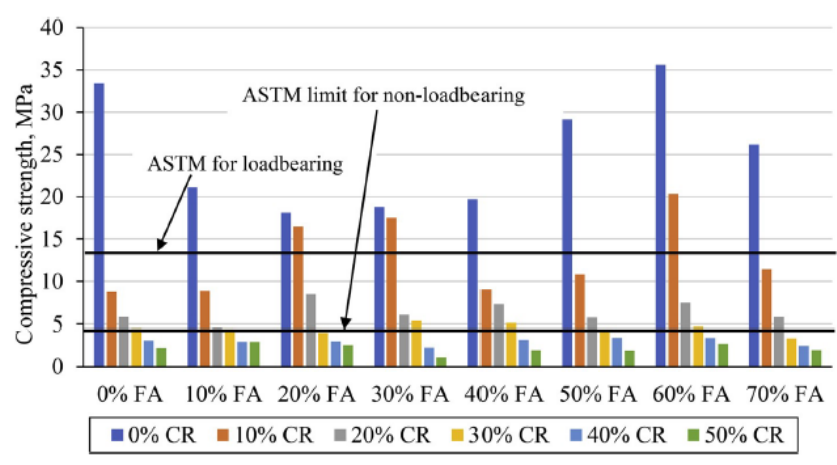

Figure 2. Compressive strength of RIB [11]

Turgut and Yesilata (2008) [4] investigated the potential use of a 0.075-4.75 mm crumb rubber-concrete combination to produce lowcost and improved heat-resistant lightweight composite bricks. Physic-mechanical and thermal insulation performances of the bricks produced using 0-70\% CR by volume were examined. Results showed that mechanical properties of $\mathrm{CR}$ bricks meet the required standards. Thermal insulation properties increases between 5-11\% depending on amount of CR in mixture.
Ling (2011) [13] replaced the fine aggregate with 5-50\% WR by volume when producing wall blocks. WR ranged from 1 to $5 \mathrm{~mm}$ in size. Three different water/binder ratio is selected as $0.45,0.50$ and 0.55 . It was obtained as the WR content in the mixture increased, there was a decrease in density and compressive strength. According to the results, it is recommended that the WR replacement should not exceed $10 \%$ by volume in load-bearing elements. In addition, this ratio is $40 \%$ for non-load bearing elements.

Mohammed et al. (2012) [14] aims to develop the acoustic, thermal and electrical properties of the hollow concrete block produced by changing fine aggregates with $C R$ in different percentages. $C R$ percentages ranged between from 0 to $50 \%$. FA and silica fume are also used to increase strength It is concluded that, if concrete block is to be used as load bearing element, maximum WR content is limited to $6.5 \%$. If concrete block is to be used as non-load bearing element maximum WR content should be $40.7 \%$. Depending on the WR replacement percentage, hollow concrete block can be produced as light and normal weight hollow block in accordance with ASTM C90 [12] and ASTMC129 [15] standards.

Aliabdo et al. (2015) [16] used CR to develop the thermal and acoustic insulation properties of concrete. The use of $100 \% \mathrm{CR}$ instead of fine aggregate by volume resulted in a 58.6\% reduction in thermal conductivity and a $69 \%$ improvement in sound insulation properties compared to the reference sample.

Sodupe-Ortega et al. (2016) [17] examined the use of $10-40 \%$ CR by volume as fine aggregate to mortars with a water/binder ratio range from 0.7-0.9 to produce bricks. The use of more than $20 \%$ rubber parts caused excessive deformations and a decrease in compressive strength.

The base reason for the improved thermal behavior of construction material produce with WR is that the rubber's thermal conductivity is between 0.1 and $0.25 \mathrm{~W} / \mathrm{mK}$, while the aggregates it replaces have a thermal conductivity of about $1.5 \mathrm{~W} / \mathrm{mK}$ [18]. On the other hand, it is well reported that the inclusion of rubber in the construction material negatively affects the mechanical properties of concrete. This is due to the poor adhesion between rubber particles and other components, and increase in the air content with inclusion of rubber [19]. To improve weak adhesion between WR and cement, Kashani et al. (2017) [20] investigates the effect of surface treatment with sodium hydroxide $(\mathrm{NaOH})$ solution with different WR contents $(0-30 \%$ by weight of total solid mass). Compression strength, porosity, thermal conductivity, sound insulation and water permeability is considered throughout the study. Results of this study have shown that when surface treatment is applied, compressive strength of concrete slightly decreases while, thermal and sound insulation behaviour are improved.

Guo et al. (2017) [21] tried five different methods to improve rubbercement adhesion. Whereas surface treatment was performed with $\mathrm{NaOH}$ and silane coupling agent, it was used for cement, cement + silica fume and cement + sodium silicate coating techniques. Consequently, it has been shown that the use of $\mathrm{NaOH}$ can develop compressive strength of concrete and increase its long-term durability. While the thermal conductivity of rubber aggregate specimens treated with $15 \% \mathrm{NaOH}$ solution decreases by $5.4 \%$, when $25 \% \mathrm{NaOH}$ solution is used, the thermal conductivity decreases by $15.5 \%$.

Kashani et al. (2018) [22] used five WR surface treatment methods (cement coating, silica fume coating, $\mathrm{NaOH}$, potassium permanganate and sulfuric acid soaking) to reduce the compressive strength loss caused by WR use in concrete composite foam. As a result, it provided a strength increase of $27-56 \%$ and the greatest improvement was seen in the sulfuric acid and silica fume coating. It can be said that coating $\mathrm{CR}$ with silica fume is one of the most suitable methods to improve the compressive strength of concrete composite foam, due to its safe, economical and low environmental risk compared to chemical treatments.

Gheni et al. (2017a) [23] investigated the mechanical performance of rubber concrete masonry units (RCMUs) with replacement rates of $0 \%$, $10 \%, 20 \%$ and $37 \%$ by volume. It can be used for partial replacement up to $20 \%$ for sand to make RCMUs. RCMUs have a lower unit weight 
but have a high rate of water absorption. Gheni et al. (2017b) [24] submitted the results of thermal conductivity and energy efficiency of RCMUs in another study. RCMUs with 10\%, 20\%, 37\% WR conten showed $9.5 \%, 20 \%$, and $45 \%$ reduction in thermal conductivity respectively, at the material level. In addition, RCMUs with $37 \%$ WR content reduce energy consumption by $41 \%$ in proportion to conventional CMUs. The differences in internal and external temperatures for the $\mathrm{CMU}$ increased from $14.3^{\circ} \mathrm{C}$ to $24^{\circ} \mathrm{C}$ for the RCMU with $37 \%$ rubber content.

WR is a sustainable lightweight aggregate for construction materials that improve its thermal and acoustic properties [17]. Fraile-Garcia et al. (2016) [25] studied the acoustics performance of hollow blocks and bricks consisting of $C R$ in varying percentages (0-20\%). It is concluded that, bricks can isolate low frequency sounds such as tractors, bass guitars and drums voices when $20 \%$ CR is replaced with fine aggregate.

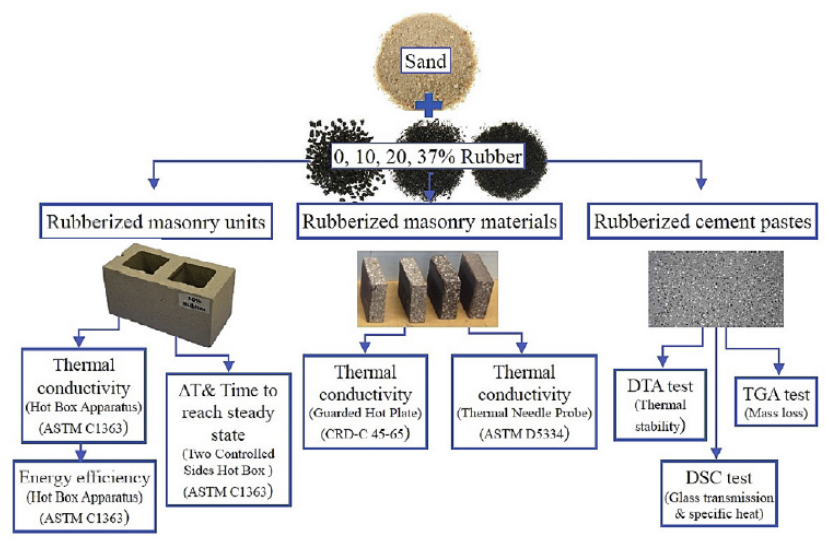

Figure 3. Gheni et al. (2017) schematic work [24]

Fraile-Garcia et al. (2018) [26] researched the thermal behavior of lightweight concrete building elements (bricks, slabs and beams) produced by using $0-10-20 \%$ of rubber particles produced from waste tires. As a result, it has been found that the thermal behavior depends on the percentage doping of the WR. WR ratio should be kept below $20 \%$ in structural elements to prevent from adverse effects of WR to mechanical properties of concrete. Despite fluctuations in the outside temperature, the internal temperature was steadied.
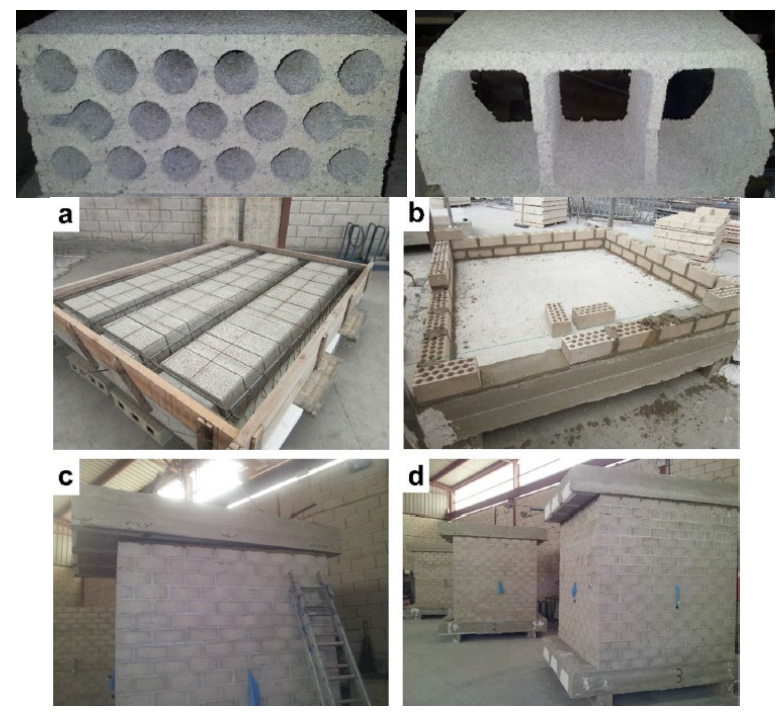

Figure 4. The elements manufactured by Fraile-Garcia et al. (2018) [26]
Wongsa et al. (2018) [27] investigated mechanical and thermal properties of lightweight geopolymer mortars containing CR produced from $100 \%$ WR as fine aggregates. The thermal conductivity of the geopolymer sample containing $100 \% \mathrm{CR}$ was $79 \%$ lower than the control sample. Additionally, the compressive strength of geopolymer mortar including CR (2.07-3.29 $\mathrm{MPa})$ fulfills the compressive strength requirement for lightweight moderate-strength concrete (2.0-14.0 $\mathrm{MPa}$ ) and is favourable for brick block production.

There are patents for brick with WR. Al-Aqeeli et al. (2018) [28] investigated non-load bearing masonry block containing CR. While the thermal conductivity of conventional blocks is $0.585 \mathrm{~W} / \mathrm{mK}$, the developed blocks range from $0.403 \mathrm{~W} / \mathrm{mK}$ (including powder $\mathrm{CR}$ ) to $0.512 \mathrm{~W} / \mathrm{mK}$ (including coarse CR). Al-Amoudi et al. (2020) [29] examined thermal insulating of masonry hollow bricks. Thermal conductivity of hollow bricks using HDPE, crushed WR and graded perlite was determined as $0.387 \mathrm{~W} / \mathrm{mK}, 0.404 \mathrm{~W} / \mathrm{mK}$ and $0.309 \mathrm{~W} / \mathrm{mK}$, respectively.

Khalid et al. (2020) [30] determined the mechanical properties of sandy cement brick containing recycled concrete aggregate (RCA) and CR waste. The samples were produced using $1.5-6.0 \%$ by weight $\mathrm{CR}$ and $15-60 \%$ RCA instead of natural sand. The mix including CR3 and RCA30 are provide high compression strength.

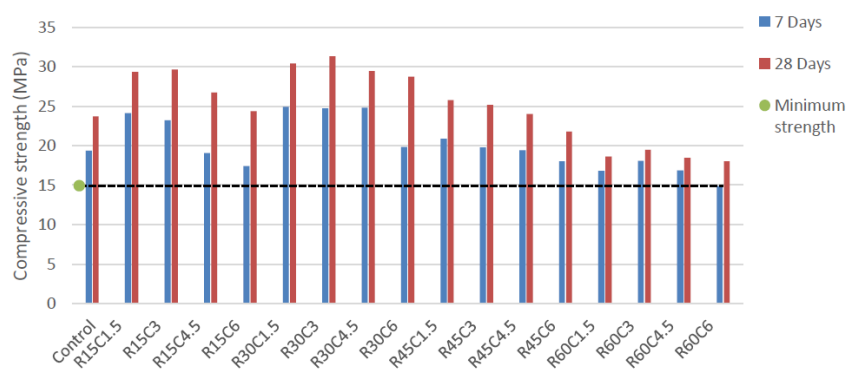

Figure 5. Compressive Strength of brick including CR and RCA [30]

Thakur et al. (2020) [31] examined the use of 5-10-15-20\% by volume of waste tires as a replacement for fine aggregates by keeping the water/binder ratio of 0.43 in the production of light wall bricks. Utilization of $20 \%$ CR compared to the reference sample showed a $55 \%$ reduction in compressive strength.

Lim et al. (2020) [32] investigated the effect of $15 \%, 30 \%$ and $45 \%$ powdered CR by volume instead of fine aggregate on the mechanical and thermal performance of concrete produced by adding it to light foamed concrete. When the amount of $\mathrm{CR}$ is $15 \%$, the reduction in compressive strength is $0.93 \%$, when the amount of $C R$ is increased to $45 \%$, the decrease in compressive strength is found as $23.97 \%$. However, the use of $45 \% \mathrm{CR}$ in lightweight foamed concrete has been reported to reduce thermal conductivity by $17.95 \%$, which means increase in insulation performance.

Chang (2020) [33] aimed to produce CR lightweight foamed concrete (CRLWC) with the best thermal and sound insulation properties. The addition of powdered CR in LWC has minimum thermal conductivity with a value of $0.2288 \mathrm{~W} / \mathrm{mK}$. Compared to powder and granular CR in LWC, powdered CR has better sound absorption coefficient.

Wang and Du (2020) [34] compared the mechanical, thermal and acoustic performance of traditional concrete, RCA, and recycled aggregate crumb rubber concrete (RCC). RCC with increased rubber content has better sound and thermal insulation than RC and NC. When $20 \%$ rubber material was used, there was a significant decrease in thermal conductivity. When the ratio of CR ratio increased to $30 \%$, largest noise reduction coefficient in the frequency range of 250-2000 $\mathrm{Hz}$ is observed. 

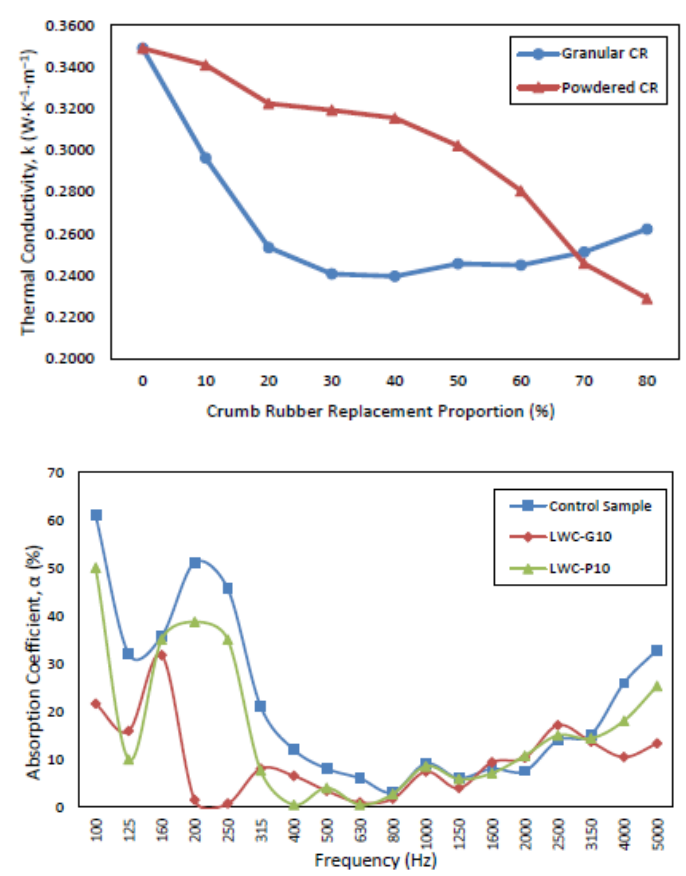

Figure 6. Thermal conductivity and absorption coefficient of CRLWC [33]
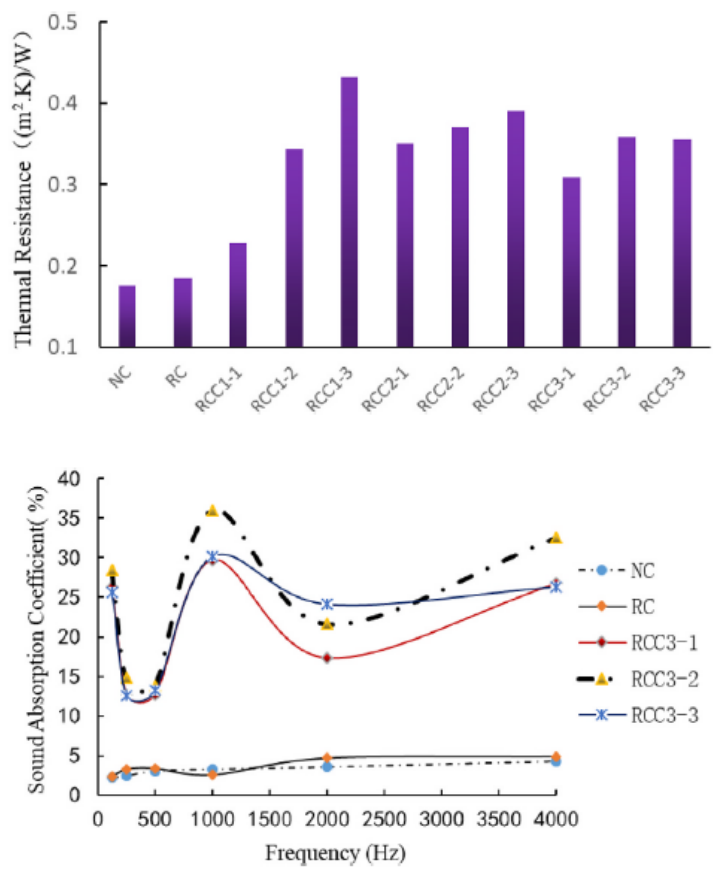

Figure 7. Thermal resistance and the absorption coefficient of RCC series [34]

\subsection{The evaluation of PET in brick}

The use of plastic has increased 20 times in the last 50 years and continues to increase. However, most of the PET waste goes into the ocean instead of being recycled. If this situation is not corrected, it is predicted that by 2050 there will be more plastic than fish in the world ocean [35].
Hiremath et al. (2014) [36] tried to produce bricks by using 60-80\% WP. The sample containing $70 \%$ WP gave the highest compressive strength with 8.16 MPa. Saika and Brito (2014) [37] examined the mechanical properties of lightweight concrete by replacing natural aggregate with PET aggregates with different shapes and sizes (coarse-PC, fine-PF, spherical/cylindrical-PP) and different volumes (5\%, $10 \%$ and 15\%). As the PET aggregate content increased, a reduction in compressive strength has occurred. The amount of decrease in strength was greater in the use of PP, PF and PC, respectively.

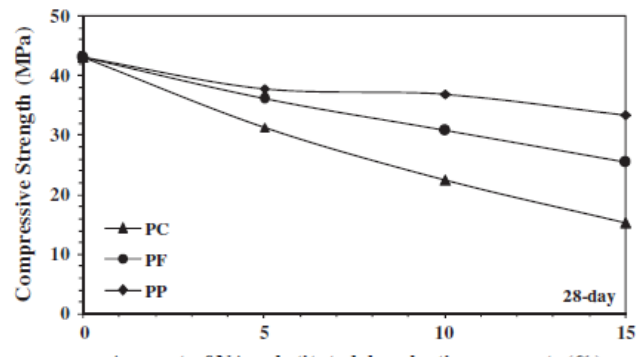

Figure 8. Compressive strength at 28-day [37]

Waroonkun et al. (2017) [38] produced bricks with cement/aggregate (sand and plastic) ratios between 1:1 - 1:6, water/binder ratio of 0.5, 0.7 and 1 . The mixture which containing cement/aggregate $=1: 3$ and water/binder= 1:2 ratios together with $80 \%$ sand and $20 \%$ WP has been shown to provide optimum compressive strength to produce a concrete block to be used to construct a non-load bearing wall.

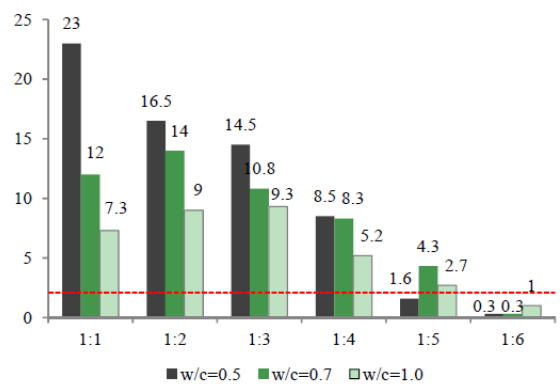

Figure 9. Compressive strength at according to W/C [38]

Kumar and Gomathi (2017) [39] investigated the thermal insulation, sound insulation and mechanical properties of bricks by using WP in varying percentages (0-20\%) instead of sand. According to the results, utilization of $5-10 \%$ WP has positive effects on compressive strength.

PET recycling has been a viable application to create thermal insulation materials in the construction industry [40]. Mondal et al. (2019) [41] examined the mechanical and thermal properties of the use of WP in brick production. While the thermal conductivity of reference bricks is $0.84 \mathrm{~W} / \mathrm{mK}$, the thermal conductivity of bricks involving WP is $0.40 \mathrm{~W} / \mathrm{mK}$.

Alaloul et al. (2020) [42] conducted experimental study to specify the mechanical and thermal properties by producing interlocking bricks using $0.75 \mathrm{~mm}$ sized PET pieces Polyurethane (PU) binder. It has been stated that the compressive strength of $5.3 \mathrm{MPa}$ is acquired for the $\mathrm{PET}(60) / \mathrm{PU}(40)$ ratio and it is favorable to be used as a non-load bearing wall brick wall. The lowest thermal conductivity was obtained for the $\mathrm{PET}(80) / \mathrm{PU}(20)$ ratio with $0.153 \mathrm{~W} / \mathrm{mK}$. 


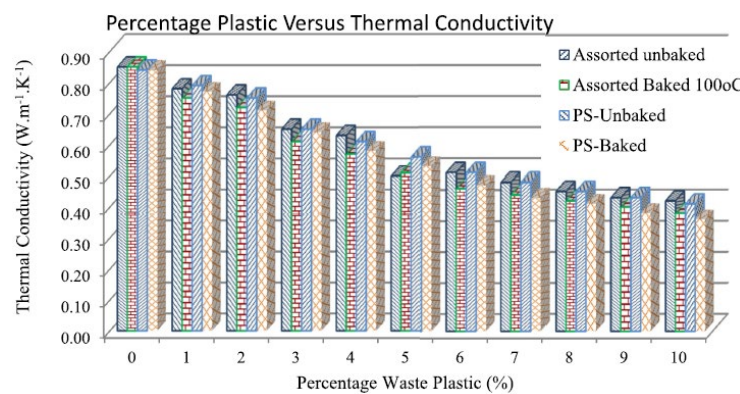

Figure 10. Thermal conductivity of brick containing WP [41]

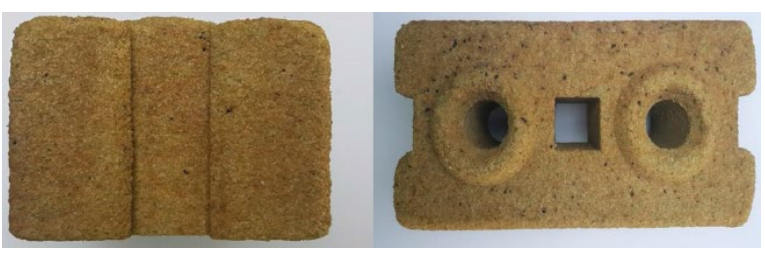

Figure 11. Interlocking brick with PET and PU binder [42]

Basha et al. (2020) [8] evaluated the mechanical and thermal properties of concrete produced using varying proportions (25-100\%) recycled plastic aggregate (RPA). The thermal conductivity, which reduced with the enhance in the amount of RPA, was in the range of 1.1-0.5 W/mK

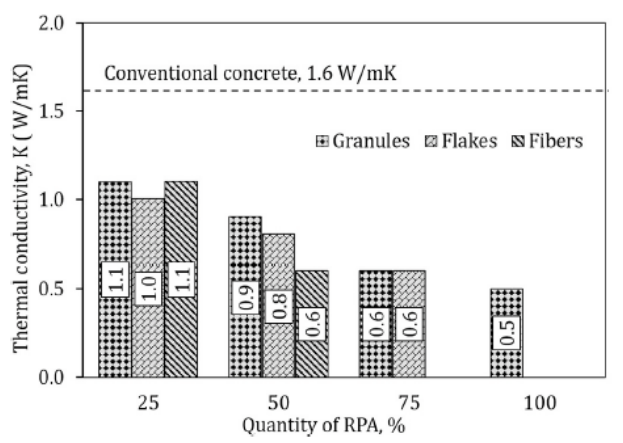

Figure 12. Thermal conductivity of RPA concrete [8]

Akinyele et al. (2020) [43] researched the use of PET in fired bricks in addition to clay. Mechanical tests are conducted after bricks are fired at $900{ }^{\circ} \mathrm{C}$ for 48 hours. Compressive strength is found as $5.15 \mathrm{MPa}, 2.30$ $\mathrm{MPa}$ and $0.85 \mathrm{MPa}$ for $0 \%, 5 \%$ and $10 \% \mathrm{PET}$ addition respectively. It is deduced that fewer than 5\% PET can be used in fired bricks.

Al-Tamimi et al. (2020) [44] developed a finite element model (FEM) to obtain the optimum geometry and placement of holes in masonry concrete blocks to decrease the thermal flow of heat from the external environment to the building. WR, PE and perlite were used to further enhance the thermal insulation (reduce thermal conductivity) of the hollow blocks. PE, WR and perlite inclusion resulted 12\%, 16\% and 33\% lower thermal than designed optimum block. The optimally designed specimen fulfilled ASTM C129 [15] requirements for non-structural walls in the way of strength and absorption. In addition, thermal conductivity is decreased by up to $40 \%$ in proportion to conventional blocks.
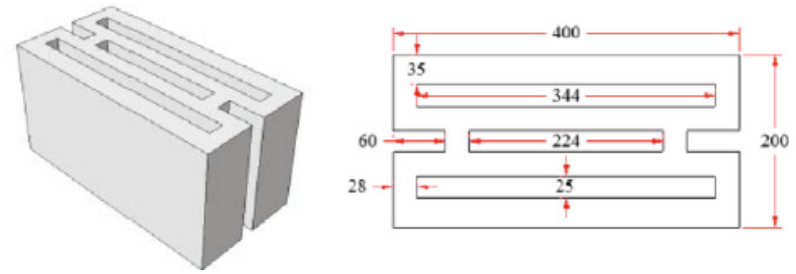

Figure 13. The best optimum hollow block was obtained Al-Tamimi et al. (2020) research [44]
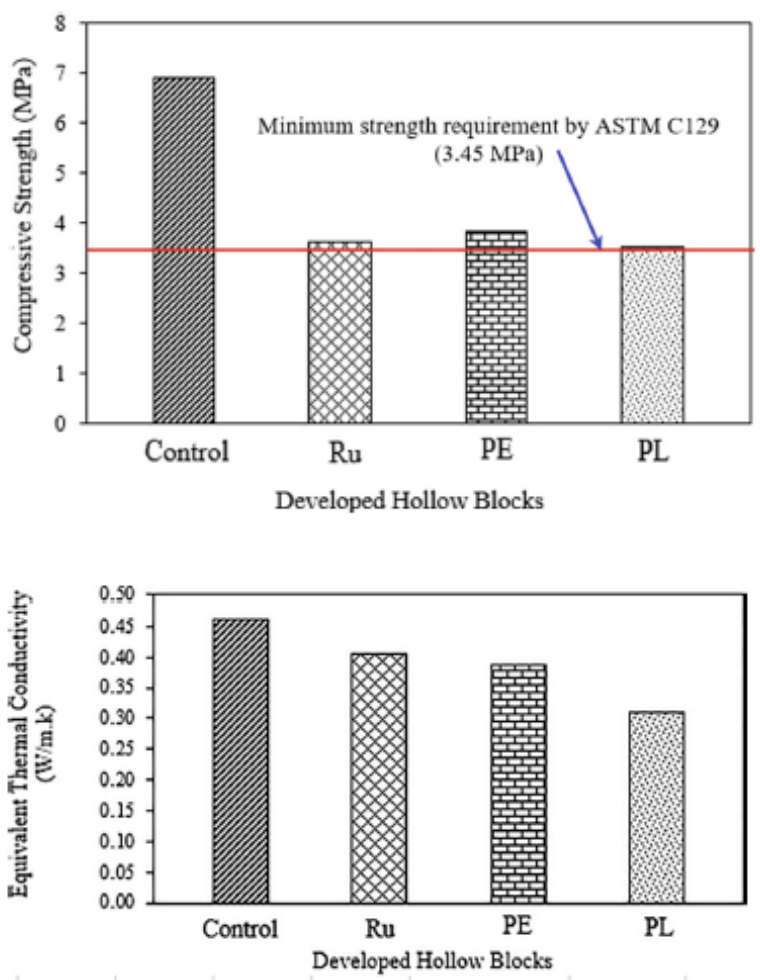

Figure 14. Compressive strengths and Equivalent thermal conductivity of hollow concrete masonry blocks [44]

Limami et al. (2020a) [45] investigated mechanical performance of unfired clay bricks using different percentages of (0-20\%) HDPE and PET. The compressive strength of the specimens using HDPE and PET decreased respect to the reference specimen, although the samples using HDPE showed higher compressive strength than those containing PET. Limami et al. (2020b) [46], in the continuation of their study, examined the effect of WP on the thermal performance of unbaked clay bricks. The thermal conductivity of the control sample, HDPE and PET added samples were found to be $0.48 \mathrm{~W} / \mathrm{mK}, 0.20 \mathrm{~W} / \mathrm{mK}$ and $0.18 \mathrm{~W} / \mathrm{mK}$, respectively. In this case, it was seen that HDPE and PET added samples had $58 \%$ and $63 \%$ gain in thermal conductivity, and $79 \%$ and $85 \%$ gain in specific heat capacities.

Marsiglio et al. (2020) [47] researched the usability of waste PET bricks to replace concrete bricks. FEM analysis was used to compare the properties of the two materials. Preliminary results have shown that PET bricks will be a safer and sustainable alternative and their insulating capacity is better.

The primary reason for the developed thermal behavior of the building material produced with PET is that the thermal conductivity of PET is $0.15 \mathrm{~W} / \mathrm{mK}$. The thermal conductivity of the most used construction material concrete is between $1.25-1.75 \mathrm{~W} / \mathrm{mK}$ [48] 


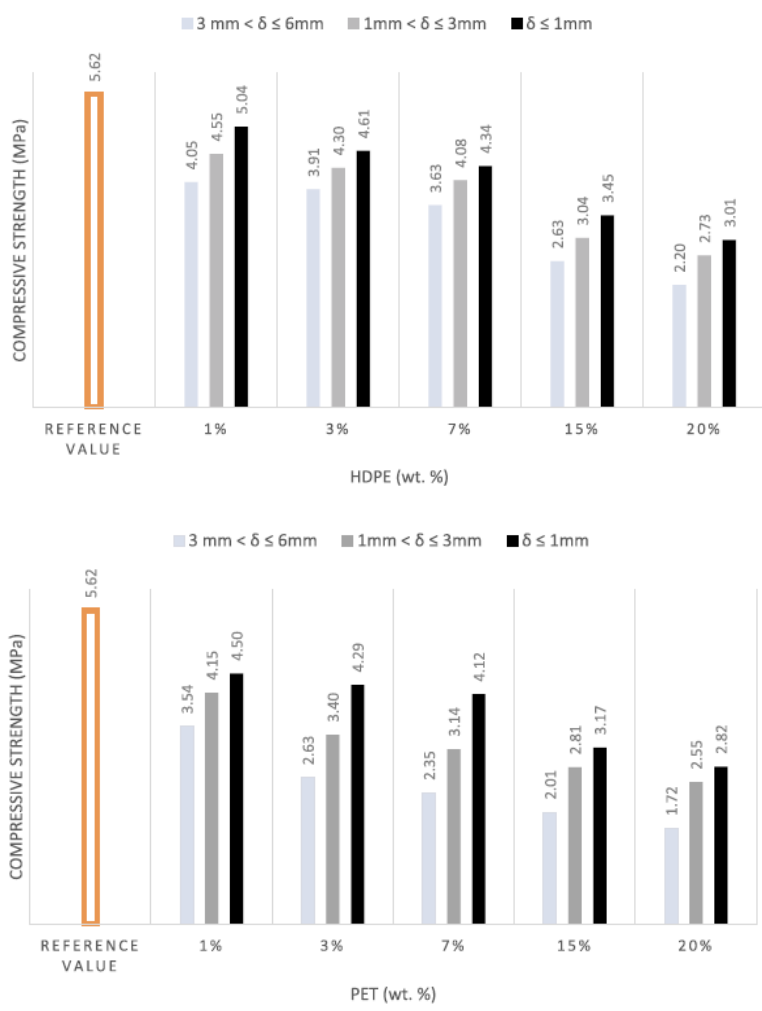

Figure 15. Compressive strength of brick specimens with WP [45]

\section{Discussion}

In this research, the properties of bricks containing various waste types, especially WR and WP, were reviewed. The using of waste materials in the production of wall units prevents the consumption of natural resources. In addition, it can be used as an effective way of disposing of these two waste materials, which improve the insulating properties of produced bricks. Table 1 shows some studies examining the production of bricks containing waste materials.

Table 1. Sustainable bricks using WR and PET

\begin{tabular}{|c|c|c|c|}
\hline $\begin{array}{c}\text { Waste Material } \\
\text { (Size, Content \%) }\end{array}$ & Reference & $\begin{array}{c}\text { Waste Material } \\
\text { (Size, Content \%) }\end{array}$ & Reference \\
\hline $\begin{array}{l}\text { FA (5\%, 15\%, } 30 \%) \\
\text { Silica Fume }(5 \% \text {, } \\
10 \%, 20 \%), \text { WR }(0.6 \\
\text { mm)(0\%, 10\%, } 25 \%, \\
50 \%)\end{array}$ & [14] & $\begin{array}{l}\text { Granules, fibers and } \\
\text { flakes WP }(3-10 \mathrm{~mm}) \\
(25 \%, \quad 50 \%, \quad 75 \% \text {, } \\
100 \%)\end{array}$ & [8] \\
\hline $\begin{array}{l}\text { WR }(\leq 0.595 \quad \mathrm{~mm} \text {, } \\
0.595-1.41 \mathrm{~mm} \text {, and } \\
2.83-3.36 \mathrm{~mm})(0 \% \text {, } \\
10 \%, 20 \%, 37 \%)\end{array}$ & {$[23,24]$} & $\begin{array}{l}\text { WP (HDPE, PET) }(<1 \\
\mathrm{mm}, 1-3 \mathrm{~mm}, 3-6 \\
\mathrm{~mm})(0 \%, 1 \%, 3 \%, 7 \% \text {, } \\
15 \%, 20 \%)\end{array}$ & {$[45,46]$} \\
\hline $\begin{array}{l}\text { WR } \\
\mathrm{mm})(100 \%)\end{array}$ & [27] & $\begin{array}{l}\text { WP }(0.75 \mathrm{~mm})(20 \% \text {, } \\
40 \%, 60 \%, 80 \%)\end{array}$ & [42] \\
\hline $\begin{array}{l}\text { WR }(0.42 \mathrm{~mm})(15 \% \text {, } \\
30 \%, 45 \%)\end{array}$ & [32] & $\begin{array}{l}\text { WR } \quad(<2 \mathrm{~mm},<4.76 \\
\mathrm{mm},<9.53 \mathrm{~mm})(20 \%) \\
\mathrm{WP}(0.6-2 \mathrm{~mm},<4.76 \\
\mathrm{mm},<9.53 \mathrm{~mm})(20 \%)\end{array}$ & [44] \\
\hline $\begin{array}{l}\text { FA (15\%), } \\
\text { WR }(0.1-4 \mathrm{~mm}, 5-10 \\
\mathrm{mm})(10 \%, 20 \%, 30 \%)\end{array}$ & [34] & $\begin{array}{l}\text { FA (15\%), } \\
\text { WP (<2 mm) (10\%) }\end{array}$ & [41] \\
\hline
\end{tabular}

Thermal and acoustic properties are also considerable as they are pertinent to the energy saving of the building, although the mechanical performance of the bricks is the primary factor [49]. As a result of the increasing amount of waste material around the world, research has been done to show that producing sound and thermal insulation materials by disposing of these materials or reusing them instead of burning them can be an answer to the waste management trouble [50]. Benkreira et al. (2011) [51] stated that it is possible to use $\mathrm{CR}$ as low cost acoustic and thermal insulation materials with similar properties to existing commercial products. According to the studied literature, the thermal performance of bricks produced with waste materials is highly effective compared to various insulating blocks. As the WP size used in the brick shrinks, the compressive strength increases and the thermal conductivity decreases. Figure 16 shows the thermal conductivity and compressive strength of bricks containing waste material.

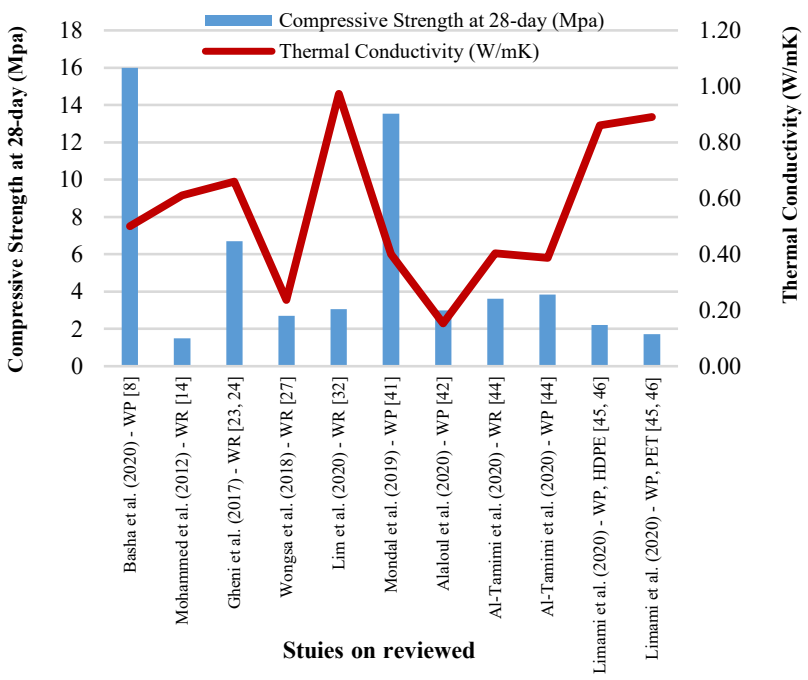

Figure 16. Compressive strength and thermal conductivity of sustainable brick

The green bricks made from waste materials instead of raw materials could be used when they meet the requirements of the standards although the application of bricks made from waste materials is limited in this day. For this reason, practicable standards should be produced to increase the production and use of wall units made of waste materials.

\section{Conclusion and Recommendation}

The reviewed articles suggest advantageous ways to reuse the waste source (WR-PET) that causes environmental pollution. Based on a review of several studies on brick containing waste rubber and PET, the following conclusions can be drawn:

- The commercial production and use of building materials produced in this way is still very limited, despite of positive outcomes of research on the use of these waste materials in brick production.

- Lightweight construction materials, which significantly reduce the dead load of the building, reduce the vibrations caused by earthquakes, thanks to their hollow structures. Therefore, bricks using waste WR and PET can be used especially in earthquake zones.

- The available studies on the production of bricks with waste $\mathrm{PET}$ is far less than the use of WR.

- The use of waste materials in brick contributes to sustainability by minimizing consumption of energy and carbon dioxide emission.

- The use of WR and PET in brick production increases acoustic attenuation while decreasing thermal conductivity. Therefore, it can increase the energy efficiency of the building while emerging into an environmentally friendly and sustainable material.

- Much more studies should be done in the future to confirm the effects of the use of WR and PET in brick producing on durability, mechanical, physical, thermal and sound properties.

\section{Declaration of Conflict of Interests}

The authors declare that there is no conflict of interest. They have no known competing financial interests or personal relationships that could have appeared to influence the work reported in this paper. 


\section{References}

[1.] Fernandes, Francisco M., Paulo B. Lourenço, and Fernando Castro. "Ancient clay bricks: manufacture and properties." Materials, Technologies and Practice in Historic Heritage Structures. Springer, Dordrecht, 2010. 29-48.

[2.] Zhang, Lianyang. "Production of bricks from waste materials-A review." Construction and building materials 47 (2013): 643-655.

[3.] Wong, Chee Lum, et al. "Potential use of brick waste as alternate concrete-making materials: A review." Journal of cleaner production 195 (2018): 226-239.

[4.] Turgut, Paki, and Bulent Yesilata. "Physico-mechanical and thermal performances of newly developed rubber-added bricks." Energy and Buildings 40.5 (2008): 679-688.

[5.] Al-Fakih, A., Mohammed, B. S., Liew, M. S., \& Nikbakht, E. Incorporation of waste materials in the manufacture of masonry bricks: An update review. Journal of Building Engineering, 21,2019: 37-54.

[6.] Thomas, B. S., \& Gupta, R. C. A comprehensive review on the applications of waste tire rubber in cement concrete. Renewable and Sustainable Energy Reviews, 54, 2016: 1323-1333.

[7.] Plastic Europe. https://www.plasticseurope.org/en/resources/publication

[8.] Basha, S. I., Ali, M. R., Al-Dulaijan, S. U., \& Maslehuddin, M. Mechanical and thermal properties of lightweight recycled plastic aggregate concrete. Journal of Building Engineering, 32, 2020: 101710

[9.] Republic of Turkey Ministry of Environment and Urbanization. (2020). https://csb.gov.tr/

[10.] Mui, E. L., Ko, D. C., \& McKay, G. Production of active carbons from waste tyres--a review. Carbon, 42(14), 2004: 2789-2805.

[11.] Al-Fakih, A., Wahab, M. A., Mohammed, B. S., Liew, M. S., Zawawi, N. A. W. A., \& As' ad, S. Experimental study on axial compressive behavior of rubberized interlocking masonry walls.Journal of Building Engineering, 29, 2020: 101107.

[12.] ASTM C90 - 99a, Standard specification for loadbearing concrete masonry units. American Society for Testing and Materials. Philadelphia June 2000. Sec.4, Volume 04.05.

[13.] Ling, T. C. Prediction of density and compressive strength for rubberized concrete blocks. Construction and Building Materials, 25(11), 2011: 4303-4306.

[14.] Mohammed, B. S., Hossain, K. M. A., Swee, J. T. E., Wong, G., \& Abdullahi, M. Properties of crumb rubber hollow concrete block. Journal of Cleaner Production, 23(1), 2012: 57-67.

[15.] ASTM, C. 129. Standard specification for non-load-bearing concrete masonry units," American Society for Testing and Materials, Philadelphia, Pa, USA, 2006.

[16.] Aliabdo, A. A., Abd Elmoaty, M., \& AbdElbaset, M. M. Utilization of waste rubber in non-structural applications. Construction and Building Materials, 91, 2015: 195-207.

[17.] Sodupe-Ortega, E., Fraile-Garcia, E., Ferreiro-Cabello, J., \& SanzGarcia, A. Evaluation of crumb rubber as aggregate for automated manufacturing of rubberized long hollow blocks and bricks. Construction and Building Materials, 106, 2016: 305-316

[18.] Kader, M. A., Abdel-Wehab, S. M., Helal, M. A., \& Hassan, H. H. Evaluation of thermal insulation and mechanical properties of waste rubber/natural rubber composite. HBRC Journal, 8(1), 2012: 69-74.

[19.] Pacheco-Torgal, F., Yining Ding, and Said Jalali. "Properties and durability of concrete containing polymeric wastes (tyre rubber and polyethylene terephthalate bottles): An overview." Construction and Building Materials 30 (2012): 714-724.

[20.] Kashani, A., Ngo, T. D., Mendis, P., Black, J. R., \& Hajimohammadi, A. A sustainable application of recycled tyre crumbs as insulator in lightweight cellular concrete. Journal of cleaner production 149, 2017: 925-935.

[21.] Guo, S., Dai, Q., Si, R., Sun, X., \& Lu, C. Evaluation of properties and performance of rubber-modified concrete for recycling of waste scrap tire. Journal of Cleaner Production, 148, 2017: 681689.

[22.] Kashani, A., Ngo, T. D., Hemachandra, P., \& Hajimohammadi, A. Effects of surface treatments of recycled tyre crumb on cementrubber bonding in concrete composite foam. Construction and Building Materials, 171, 2018: 467-473.

[23.] Gheni, A. A., ElGawady, M. A., \& Myers, J. J. Mechanical Characterization of Concrete Masonry Units Manufactured with Crumb Rubber Aggregate. ACI Materials Journal, 114(1), 2017.
[24.] Gheni, A. A., ElGawady, M. A., \& Myers, J. J. Thermal characterization of cleaner and eco-efficient masonry units using sustainable aggregates. Journal of Cleaner Production, 165, 2017: 980-993.

[25.] Fraile-Garcia, E., Ferreiro-Cabello, J., Defez, B., \& Peris-Fajanes, G. Acoustic behavior of hollow blocks and bricks made of concrete doped with waste-tire rubber. Materials, 9(12), 2016: 962.

[26.] Fraile-Garcia, E., Ferreiro-Cabello, J., Mendivil-Giro, M., \& San Vicente-Navarro, A. Thermal behaviour of hollow blocks and bricks made of concrete doped with waste tyre rubber. Construction and Building Materials, 176, 2018: 193-200.

[27.] Wongsa, A., Sata, V., Nematollahi, B., Sanjayan, J., \& Chindaprasirt, P. Mechanical and thermal properties of lightweight geopolymer mortar incorporating crumb rubber. Journal of Cleaner Production, 195, 2018: 1069-1080.

[28.] Al-Aqeeli, N. M., Assehdi, H. M., \& Maslehuddin, M. (2018). U.S Patent No. 10,059,626. Washington, DC: U.S. Patent and Trademark Office.

[29.] Al-Amoudi, O. S. M. B., Al-osta, M. A. M., \& Al-tamimi, A. S. B. (2020). U.S. Patent No. 10,538,916. Washington, DC: U.S. Patent and Trademark Office.

[30.] Khalid, F. S., Aminuddin, M. Y. A., Shahidan, S., Irwan, J. M., \& Ibrahim, M. W. (2020, September). The Mechanical Properties of Brick Containing Recycled Concrete Aggregate and Crumb Rubber as Sand Replacement. In IOP Conference Series: Materials Science and Engineering (Vol. 917, No. 1, p. 012020). IOP Publishing.

[31.] Thakur, A., Senthil, K., Sharma, R., \& Singh, A. P. Employment of crumb rubber tyre in concrete masonry bricks. Materials Today: Proceedings, 2020.

[32.] Lim, Z. H., Lee, F. W., Mo, K. H., Kwong, K. Z., \& Yew, M. K. (2020, January). The Influence of Powdered Crumb Rubber on the Mechanical Properties and Thermal Performance of Lightweight Foamed Concrete. In IOP Conference Series: Materials Science and Engineering (Vol. 739, No. 1, p. 012016). IOP Publishing.

[33.] Chang, J. M. (2020). A Study of Thermal and Acoustic Performances of Crumb Rubber Lightweight Foamed Concrete with Density of $1050 \mathrm{Kg} / \mathrm{M} 3-1150 \mathrm{Kg} / \mathrm{M} 3$ (Doctoral dissertation, UTAR).

[34.] Wang, J., \& Du, B. Experimental studies of thermal and acoustic properties of recycled aggregate crumb rubber concrete. Journal of Building Engineering, 32, 2020: 101836.

[35.] World Economic Forum. (Januray, 2016). The New Plastics Economy Rethinking the future of plastics. http://www3.weforum.org/docs/WEF_The_New_Plastics_Econo my.pdf

[36.] Hiremath, P. M., \& Shetty, S. Utilization of waste plastic in manufacturing of plastic-soil bricks, 2014.

[37.] Saikia, N., \& de Brito, J. Mechanical properties and abrasion behaviour of concrete containing shredded PET bottle waste as a partial substitution of natural aggregate. Construction and building materials, 52, 2014: 236-244.

[38.] Waroonkun, T., Puangpinyo, T., \& Tongtuam, Y. The Development of a Concrete Block Containing PET Plastic Bottle Flakes. Journal of Sustainable Development, 10(6), 2017: 186.

[39.] KUMAR, K. Prem; GOMATHI, M. Production of Construction Bricks by Partial Replacement of Waste Plastics. IOSR Journal of Mechanical and Civil Engineering (IOSR-JMCE) e-ISSN, 2017, 2278-1684.

[40.] Yesilata, B., Isıker, Y., \& Turgut, P. Thermal insulation enhancement in concretes by adding waste PET and rubber pieces. Construction and Building Materials, 23(5), 2009: 18781882.

[41.] Mondal, M. K., Bose, B. P., \& Bansal, P. Recycling waste thermoplastic for energy efficient construction materials: An experimental investigation. Journal of environmental management, 240, 2019: 119-125.

[42.] Alaloul, W. S., John, V. O., \& Musarat, M. A. Mechanical and Thermal Properties of Interlocking Bricks Utilizing Wasted Polyethylene Terephthalate. International Journal of Concrete Structures and Materials, 14, 2020: 1-11.

[43.] Akinyele, J. O., Igba, U. T., \& Adigun, B. G. Effect of waste PET on the structural properties of burnt bricks. Scientific African, 7 2020: e00301.

[44.] Al-Tamimi, A. S., Al-Amoudi, O. S. B., Al-Osta, M. A., Ali, M. R., \& Ahmad, A. Effect of insulation materials and cavity layout on 
heat transfer of concrete masonry hollow blocks. Construction and Building Materials, 254, 2020: 119300.

[45.] Limami, H., Manssouri, I., Cherkaoui, K., \& Khaldoun, A. Study of the suitability of unfired clay bricks with polymeric HDPE \& PET wastes additives as a construction material. Journal of Building Engineering, 27, 2020: 100956.

[46.] Limami, H., Manssouri, I., Cherkaoui, K., Saadaoui, M., \& Khaldoun, A. Thermal performance of unfired lightweight clay bricks with HDPE \& PET waste plastics additives. Journal of Building Engineering, 30, 2020: 101251.

[47.] Marsiglio, L., Cheng, S., Falk, E., Fugh, A., Mulvaney, K., Slocum, B., ... \& Mehta, K. (2020, November) Comparing the Properties of Polyethylene Terephthalate (PET) Plastic Bricks to Conventional Concrete Masonry Units, IEEE Global Humanitarian Technology Conference (GHTC).

[48.] Callister Jr, W. D., \& Rethwisch, D. G. (2020). Fundamentals of materials science and engineering: an integrated approach. John Wiley \& Sons.

[49.] Zhang, Z., Wong, Y. C., Arulrajah, A., \& Horpibulsuk, S. A review of studies on bricks using alternative materials and approaches. Construction and Building Materials, 188, 2018: 1101-1118.

[50.] Abu-Jdayil, B., Mourad, A. H., Hittini, W., Hassan, M., \& Hameedi, S. Traditional, state-of-the-art and renewable thermal building insulation materials: An overview. Construction and Building Materials, 214, 2019: 709-735.

[51.] Benkreira, H., Khan, A., \& Horoshenkov, K. V. Sustainable acoustic and thermal insulation materials from elastomeric waste residues. Chemical Engineering Science, 66(18), 2011: 4157-4171.

\section{How to Cite This Article}

Karslıoğlu, A., Balaban, E., and Onur, M. I., Insulation Properties of Bricks with Waste Rubber and Plastic: A Review, Journal of Nature, Science \& Technology, 1(2021), 20-27.

https://doi.org/10.36937/janset.2021.001.004 